in vivo $35: 1007-1015(2021)$

doi:10.21873/invivo.12344

\title{
An Observational Study on Breast Cancer Survival and Lifestyle Related Risk Factors
}

\author{
ANNE KREKLAU $^{1}$, IVONNE NEL ${ }^{1}$, SABINE KASIMIR-BAUER ${ }^{2}$, RAINER KIMMIG ${ }^{2}$, \\ ANNA CHRISTINA FRACKENPOHL ${ }^{2}$ and BAHRIYE AKTAS ${ }^{1,2}$ \\ ${ }^{1}$ Department of Gynecology and Obstetrics, University Hospital Leipzig, Leipzig, Germany; \\ ${ }^{2}$ Department of Gynecology and Obstetrics, University Hospital Essen, Essen, Germany
}

\begin{abstract}
Background/Aim: Breast cancer survivors are increasingly interested in lifestyle modifications in order to reduce the risk of recurrence and mortality. Therefore, we aimed to study the association between survival and lifestyle related risk factors such as obesity, alcohol intake, smoking, medication and atopic diseases. Patients and Methods: In this observational single center study, clinicopathological parameters of 635 women with primary breast cancer were sampled. A logistic regression model was applied to investigate correlations among clinical data and various life style related factors. Patients were stratified according to lifestyle and treatment characteristics. Cox regression and the Kaplan-Meier method were used to analyze survival differences in various patient subsets and to identify possible prognostic factors. Results: Logistic regression analysis indicated a correlation between low Body Mass Index (BMI) and extended progression-free survival (PFS). Cox regression showed that patients not using beta-blockers had a significantly prolonged overall survival (OS) compared to beta-blocker users [hazard ratio $(H R)=3.7 ; 95 \%$ confidence interval $(C I)=1.66-8.14, \quad p=0.01]$. Apparently, the clincopathological parameters including BMI, HER2-, estrogen receptor $(E R)$ and progesteron receptor $(P R)$-status as well as treatment with chemo-, radio- and endocrine therapy did not play a role regarding the survival differences between beta-blocker users and non-users. Conclusion: Patients not using beta-blockers appeared to benefit from extended PFS and OS. Further, patients with a rather low
\end{abstract}

This article is freely accessible online.

Correspondence to: Dr. Anne Kreklau, Department of Gynecology, University Hospital Leipzig, Liebigstrasse 20A, 04103 Leipzig, Saxonia, Germany. Tel: +49 3419720911, e-mail: anne.kreklau@medizin.uni-leipzig.de

Key Words: Breast cancer, lifestyle factor, BMI, beta-blockers, alcohol consumption, smoking, cancer-related risk factor, obesity.
BMI $\left(<30 \mathrm{~kg} / \mathrm{m}^{2}\right)$ seemed to have a survival benefit compared to obese patients. Particularly, among postmenopausal women, beta-blocker intake and obesity appeared to be possible life style related prognostic factors that could be used for patient stratification.

Breast cancer is the most frequent cancer in women (1). In Germany, approximately 70,000 new cases are diagnosed per year. About $30 \%$ of patients are younger than 55 years. Improved diagnostic tools and novel treatment options have resulted in a 5-year survival rate of $88 \%$ (2). Women surviving breast cancer are increasingly interested in adapting their lifestyle in order to reduce the risk of cancer recurrence. Cancer related risk factors that might be influenced by the patients' lifestyle are categorized as modifiable lifestyle factors, e.g. obesity, alcohol intake, cigarette smoking, breast feeding and physical exercise (3$6)$. Its complex etiology involves a large range of factors which might influence the incidence as well as the prognosis. However, most studies have analyzed the influence of those factors to the incidence but not to the prognosis.

Since 1999, the proportion of obese patients in Germany, defined by a Body-mass index (BMI) greater than $30 \mathrm{~kg} / \mathrm{m}^{2}$, has been raising from $48 \%$ to $52 \%$ (7). Obesity was repeatedly reported to be correlated with breast tumors of larger size, lymph node positivity and poor prognosis $(4,8)$. It was also reported to be inversely associated with the risk of breast cancer diagnosed at premenopausal ages $(4,9,10)$ and positively associated with the risk for contralateral breast cancer after menopause $(11,12)$. Furthermore, excess weight and obesity were shown to be related to a $30-45 \%$ increased risk of breast cancer recurrence and death, irrespective of menopausal or hormone receptor status (6, 13). Particularly in postmenopausal and hormone sensitive patients, tumor progression appeared to be influenced by the relationship between obesity, inflammation and tumor microenvironment (14).

Apart from obesity, hypertension and diabetes are also global lifestyle diseases on the increase (15). Therefore, 
some of the breast cancer patients are treated with medication such as beta-blockers or metformin. Betablockers are used to reduce hypertension by competing with the adrenergic hormones epinephrine and norepinephrine to bind beta-adrenergic receptors and subsequently inhibit the stress response. Concerning the use of beta-blockers, preclinical observations suggested a reduction of metastasis, cancer recurrence and an improved clinical outcome due to the neuroendocrine regulation of breast tumor progression, mediated through activation of the sympathetic nervous system and the release of epinephrine and norepinephrine $(16,17)$. Inhibiting the beta2-adrenergic pathway was suggested to reduce breast cancer progression and mortality $(18,19)$. However, contradictive results were published in some recent meta-analyses that revealed no beneficial effect of beta-blocker use on cancer prognosis (20-22).

Patients suffering from type 2 diabetes might use metformin which is widely prescribed as an antihyperglycemic drug and recently reported to be associated with improved survival in breast cancer patients (23). Due to its function in multiple cancer related signaling pathways, metformin has been considered as a possible therapeutic agent in cancer treatment. It was shown to have antiproliferative and pro-apoptotic effects in several cases including melanoma, esophageal, lung, colon, prostate and breast cancer (24).

To treat symptoms associated with menopause, some women undergo hormonal replacement therapy; it is still under debate whether this therapy affects the incidence of breast cancer. Women's Health Initiative (WHI) data suggest that both estrogen alone as well as estrogen-progestin therapy, are associated with an elevated breast cancer incidence rate (25).

Up to now, several lifestyle investigating studies have focused on the breast cancer incidence rates but not on the patients' outcome. Therefore, the objective of this observational study was to evaluate whether potentially modifiable lifestyle factors might have an impact on the prognosis of breast cancer survivors. We sought to scrutinize possible associations between survival time, clinicopathological characteristics and lifestyle related risk factors like obesity, alcohol consumption, smoking, atopic diseases and the use of beta-blockers, metformin, or hormone replacement therapy in patients with primary breast cancer.

\section{Patients and Methods}

Informed consent and study population. This Study was in accordance with the ethical standards of the institutional and national research committee and with the 1964 Helsinki Declaration and its later amendments or comparable ethical standards. The Human Investigation Committee (IRB) of University Duisburg-Essen (Germany) approved this study. Written informed consent was obtained from all patients before participation this study. A total of
635 women, aged 27 to 86 years, diagnosed with invasive breast cancer were enrolled during 2004 and 2010 in the Department of Gynecology and Obstetrics of the University Hospital Essen. Exclusion criteria were defined as necessity of a neoadjuvant systemic therapy or primary diagnosis of metastatic breast cancer. The patients' baseline characteristics including age, height, weight, menopausal stage, smoking, alcohol intake, atopic diseases, medication and use of hormone replacement therapy were recorded at inpatient admission. Hormonal replacement therapy included estrogen only and estrogen-progestin therapy. BMI was calculated from height and weight and patients were categorized into one of the following four groups according to the World Health Organisation (WHO) classification: underweight $\left(<18.5 \mathrm{~kg} / \mathrm{m}^{2}\right)$, normal range $\left(18.5-24.99 \mathrm{~kg} / \mathrm{m}^{2}\right)$, overweight $\left(25-29.99 \mathrm{~kg} / \mathrm{m}^{2}\right)$ and obese $(>30$ $\mathrm{kg} / \mathrm{m}^{2}$ ). The available patient information is summarized in Table I.

Tumor characteristics including tumor size, lymph node involvement, grade, histology, estrogen- (ER), progesterone- (PR) and HER2-receptor status were recorded from medical reports of the Department of Pathology of the University Hospital Essen and are listed in Table II. Data on radiation therapy, adjuvant chemotherapy, use of endocrine therapy, tumor recurrence, metastasis or death were collected from the detailed medical records as well as telephone questionnaires answered by either the patients themselves or their general practitioners or gynecologists.

Statistical analysis. A logistic regression model was chosen to analyze relations between clinicopathological parameters and various lifestyle related factors. Since the hazard i.e. the probability of the endpoint (recurrence of disease), is supposed to be proportional in the patient groups, a Cox regression model was used to analyze the effect of the aforementioned lifestyle factors as possible predictor variables on the patients' survival time. The effect of lifestyle related risk factors was expressed as hazard ratios (HR) and $95 \%$ confidence intervals $(\mathrm{CI})$.

Univariate and multivariate analyses were used to describe overall survival (OS) time curves as well as progression free survival (PFS), based on correlations to the listed lifestyle factors. The BMI was categorized using the definition of obesity described by the WHO. Using a BMI of 30 as a cut-off value for obesity, patients were divided into low (BMI $\left.<30 \mathrm{~kg} / \mathrm{m}^{2}\right) v s$. high (BMI $>30$ $\mathrm{kg} / \mathrm{m}^{2}$ ) BMI subgroups. The Kaplan-Meier method was used to test correlations between PFS and lifestyle factors. A two-tailed $p$-Value less than 0.05 was considered the threshold of statistical significance. All statistical analyses were performed by using SAS (Version 9.2 for Windows, ACOMED, Leipzig, Germany).

\section{Results}

The median age of the 635 breast cancer patients enrolled was 60.8 years, ranging between 27 and 86 years. The median BMI was $25.3 \mathrm{~kg} / \mathrm{m}^{2} ; 31 \%$ of the patients had a BMI $<25 \mathrm{~kg} / \mathrm{m}^{2}, 47 \%$ an intermediate BMI of $25-30 \mathrm{~kg} / \mathrm{m}^{2}$ and $22 \%$ a BMI $>30 \mathrm{~kg} / \mathrm{m}^{2}$. Menopausal status had already been passed by $74 \%$ of the women while $14 \%$ were premenopausal. $68 \%$ were non-smokers and $82 \%$ did not consume alcohol regularly. $45 \%$ of the patients were suffering from at least one atopic disease and beta-blockers were used in $21 \%$ of the cases. Metformin was used by $6 \%$ and hormonal replacement therapy by $26 \%$ of the women. 
Table I. Baseline patient characteristics.

\begin{tabular}{lrr}
\hline Characteristic & N & $\%$ \\
\hline Age & & \\
$\quad<60$ years & 305 & $48 \%$ \\
$>60$ years & 330 & $52 \%$ \\
BMI & & \\
$<25$ & 200 & $31 \%$ \\
$25-30$ & 131 & $47 \%$ \\
$>30$ & 95 & $22 \%$ \\
Menopausal status & & \\
$\quad$ Premenopausal & 92 & $14 \%$ \\
Perimenopausal & 73 & $11 \%$ \\
$\quad$ Postmenopausal & 470 & $74 \%$ \\
Hormone replacement therapy & 92 & $26 \%$ \\
No hormone replacement therapy & 260 & $74 \%$ \\
Smokers & 125 & $32 \%$ \\
Non-smokers & 267 & $68 \%$ \\
Alcohol consumption & 67 & $18 \%$ \\
No alcohol consumption & 309 & $82 \%$ \\
Beta-blockers & 83 & $21 \%$ \\
No beta-blockers & 307 & $79 \%$ \\
Metformin & 22 & $6 \%$ \\
No metformin & 365 & $94 \%$ \\
Atopic disease & 187 & $45 \%$ \\
No atopic disease & 230 & $55 \%$ \\
\hline & & \\
\hline & &
\end{tabular}

Early stage of breast cancer, defined as T1 was diagnosed in $62 \%$ of the patients. A positive lymph node status was found in $34 \%$ of the cases. The tumors were positive for estrogen- or progesterone receptor in $82 \%$ and $73 \%$ of the patients, respectively, whereas $16 \%$ had a HER2-positive and $12 \%$ a triple negative receptor status. $85 \%$ of the women received systemic chemotherapy, $61 \%$ were treated with radiotherapy and in $81 \%$ of the cases endocrine therapy was applied.

Correlations between patient characteristics and lifestyle. The logistic regression analysis confirmed that the patients age and BMI (defined by BMI $<30 \mathrm{~kg} / \mathrm{m}^{2}$ ) were significantly associated with the menopausal status ( $p=0.004$ and 0.01 , respectively). The number of obese women (BMI $>30$ $\mathrm{kg} / \mathrm{m}^{2}$ ) was significantly lower among women $\leq 60$ years compared to women $>60$ years. As expected, the use of hormone replacement therapy was significantly increased in the postmenopausal group $(p=0.002)$ and in women $>60$ years $(p=0.0003)$ compared to patients who were premenopausal and $<60$ years, respectively.

Furthermore, the statistical model revealed that the BMI was significantly correlated with smoking $(p=0.03)$ as well as the use of beta-blockers $(p<0.0001)$ and metformin ( $p=0.03)$, respectively. The number of obese women (BMI $>30 \mathrm{~kg} / \mathrm{m}^{2}$ ) was significantly elevated among non-smokers compared to patients who smoked. Interestingly, smoking
Table II. Baseline tumor characteristics.

\begin{tabular}{|c|c|c|}
\hline Characteristic & $\mathrm{N}$ & $\%$ \\
\hline \multicolumn{3}{|l|}{ Tumor size } \\
\hline Tis & 3 & $<1 \%$ \\
\hline $\mathrm{T} 1$ & 395 & $62 \%$ \\
\hline $\mathrm{T} 2$ & 203 & $32 \%$ \\
\hline $\mathrm{T} 3$ & 23 & $4 \%$ \\
\hline $\mathrm{T} 4$ & 10 & $2 \%$ \\
\hline \multicolumn{3}{|l|}{ Lymph node positivity } \\
\hline No & 419 & $66 \%$ \\
\hline $\mathrm{N} 1$ & 195 & $31 \%$ \\
\hline $\mathrm{N} 2$ & 12 & $2 \%$ \\
\hline N3 & 7 & $1 \%$ \\
\hline \multicolumn{3}{|l|}{ Grade } \\
\hline G1 & 112 & $18 \%$ \\
\hline G2 & 341 & $54 \%$ \\
\hline G3 & 180 & $28 \%$ \\
\hline \multicolumn{3}{|l|}{ Metastasis } \\
\hline M0 & 635 & $100 \%$ \\
\hline \multicolumn{3}{|l|}{ Histological subtype } \\
\hline Ductal invasive & 480 & $76 \%$ \\
\hline Lobular invasive & 86 & $14 \%$ \\
\hline Others & 69 & $11 \%$ \\
\hline \multicolumn{3}{|l|}{ Estrogen receptor (ER) } \\
\hline Positive & 520 & $82 \%$ \\
\hline Negative & 113 & $18 \%$ \\
\hline \multicolumn{3}{|l|}{ Progesteron receptor (PR) } \\
\hline Positive & 463 & $73 \%$ \\
\hline Negative & 170 & $27 \%$ \\
\hline \multicolumn{3}{|l|}{ Her2 status } \\
\hline Positive & 99 & $16 \%$ \\
\hline Negative & 532 & $84 \%$ \\
\hline Triple negative & 75 & $12 \%$ \\
\hline Adjuvant chemotherapy & 324 & $61 \%$ \\
\hline No adjuvant chemotherapy & 204 & $39 \%$ \\
\hline Adjuvant radiation & 455 & $85 \%$ \\
\hline No adjuvant radiation & 83 & $15 \%$ \\
\hline Adjuvant endocrine therapy & 511 & $81 \%$ \\
\hline No adjuvant endocrine therapy & 117 & $19 \%$ \\
\hline
\end{tabular}

was significantly correlated with age $(p<0.0001)$ and menopausal status $(p=0.002)$ suggesting that elder women ( $>60$ years) were smoking less frequently as compared to younger ( $<60$ years). Consequently, the number of nonsmokers was significantly increased in the postmenopausal group. However, the use of beta-blockers and metformin was significantly increased in the obese group compared to nonobese women (BMI $\leq 30 \mathrm{~kg} / \mathrm{m}^{2}$ ). Even though not significantly, the BMI was correlated by trend with the intake of alcohol $(p=0.05)$. The applied lifestyle analysis suggested that younger women $(<60$ years) were smoking more frequently and were less obese $\left(B M I<30 \mathrm{~kg} / \mathrm{m}^{2}\right)$. Consequently, elder women ( $>60$ years) appeared to be nonsmokers, consumed less alcohol, but tended to be overweight and used beta-blockers more frequently. 

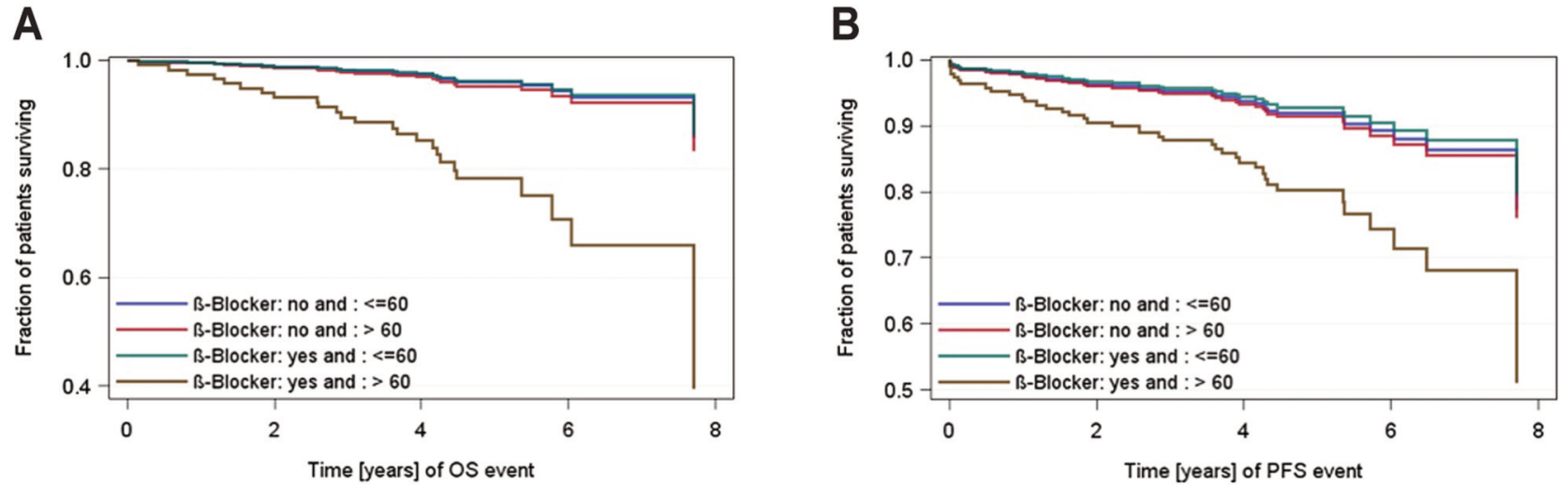

Figure 1. Patients were stratified according to age ( $>60$ or $<60$ years) and use of beta-blockers resulting in four subsets of patients. Kaplan-Meier analysis showed that $A)$ overall survival $(H R=5.09 ; 95 \% C I=1.91-3.57 ; p=0.001)$ and $B)$ PFS $(H R=2.45 ; 95 \% C I=1.07-5.62 ; p=0.03)$ were significantly decreased in elder patients (>60 years) using beta-blockers as compared to all other patient groups.

The statistical data indicated that atopic diseases might be associated with lymphangiosis carcinomatosa $(p=0.03)$ as well as the HER2 status $(p=0.02)$. Patients without allergies were less frequently suffering from lymphangiosis as compared to allergic patients. Furthermore, the number of HER2 negative patients was significantly increased in the allergic group as compared to patients without allergic diseases.

Is survival associated to lifestyle? The logistic regression indicated a correlation between the patients BMI and PFS. Although the difference was not statistically significant, patients with BMI $<30 \mathrm{~kg} / \mathrm{m}^{2}$ were suffering less frequently from recurrence, as compared to obese patients with BMI $>30$ $\mathrm{kg} / \mathrm{m}^{2}$ ( $p=0.09$ ). Uni- and bivariate Cox regression analysis confirmed that patients with BMI $<30 \mathrm{~kg} / \mathrm{m}^{2}$ tended to have a prolonged PFS $(\mathrm{HR}=1.9 ; 95 \% \mathrm{CI}=0.97-3.69 ; p=0.06)$ as compared to patients with $\mathrm{BMI}>30 \mathrm{~kg} / \mathrm{m}^{2}$. There was no statistically significant association between BMI and OS. When patients were stratified into BMI $<25 \mathrm{~kg} / \mathrm{m}^{2} v s$. BMI $25-30 \mathrm{~kg} / \mathrm{m}^{2} v s$. BMI $>30 \mathrm{~kg} / \mathrm{m}^{2}$, Cox regression analysis indicated that PFS and OS were increased in patients with intermediate BMI $\left(25-30 \mathrm{~kg} / \mathrm{m}^{2}\right)$ as compared to patients with low $\left(<25 \mathrm{~kg} / \mathrm{m}^{2}\right)$ and high BMI $\left(>30 \mathrm{~kg} / \mathrm{m}^{2}\right)$, respectively.

Uni- and bivariate survival analysis with regard to OS and PFS did not reveal any statistically relevant association regarding cigarette smoking, alcohol intake and atopic diseases. Although logistic regression indicated that metformin intake was associated with patient age $(p=0.003)$ and BMI $(p=0.03)$, uni- and bivariate survival analysis showed no significant correlation with OS $(\mathrm{HR}=2.65 ; 95 \%$ $\mathrm{CI}=0.79-8.92 ; p=0.11)$ and PFS $(\mathrm{HR}=1.6 ; 95 \% \mathrm{CI}=0.49$ $5.24 ; p=0.43)$.

The use of beta-blockers in women with a BMI $>30 \mathrm{~kg} / \mathrm{m}^{2}$ and age $>60$ years was significantly correlated with a

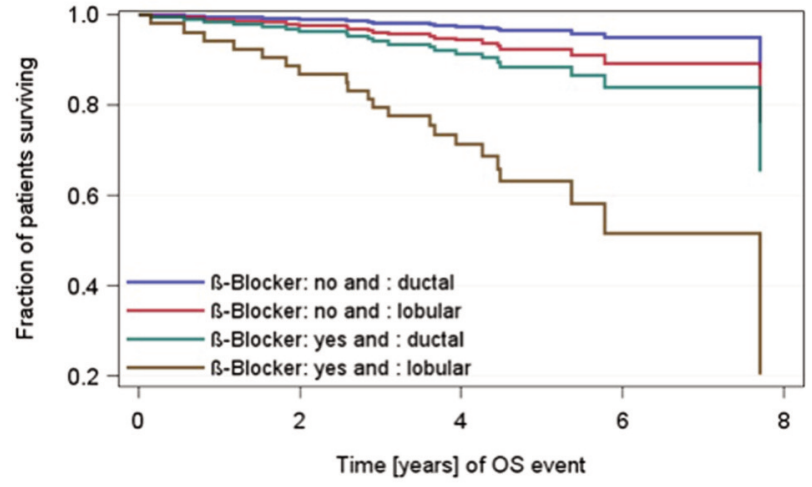

Figure 2. Patients were stratified into ductal or lobular breast cancer and usage of beta-blockers resulting in four subsets of patients. KaplanMeier analysis showed that patients with lobular subtype using betablockers had a significantly shorter overall survival as compared to all other patient groups $(H R=3.4 ; 95 \%$ CI: 1.22-9.38; $p=0.02$ and $H R=5.8 ; 95 \% C I=1.04-2.38 ; p=0.05)$.

decreased OS as compared to women without taking betablockers. Cox regression showed that patients not using betablockers had a significantly prolonged OS as compared to beta-blocker users $(\mathrm{HR}=3.7 ; 95 \% \mathrm{CI}=1.66-8.14 ; p=0.01)$. Even though not significant, PFS was increased when patients were not using beta-blockers $(\mathrm{HR}=1.90$; 95\% $\mathrm{CI}=0.96-3.76 ; p=0.07)$. Bivariate analysis demonstrated that beta-blocker treatment was significantly correlated with survival. Particularly patients with high BMI $\left(>30 \mathrm{~kg} / \mathrm{m}^{2}\right)$ that were using beta-blockers had a significantly decreased PFS (HR=11.9; 95\% CI=1.38-3.87; $p=0.02)$.

The patients' age was significantly correlated with BMI, therefore, patients $>60$ years had a significantly shorter PFS and $\mathrm{OS}$ when using beta-blockers $(\mathrm{HR}=5.09$; 95\% $\mathrm{CI}=1.91$ 3.57; $p=0.001$;) (Figure 1). 
A

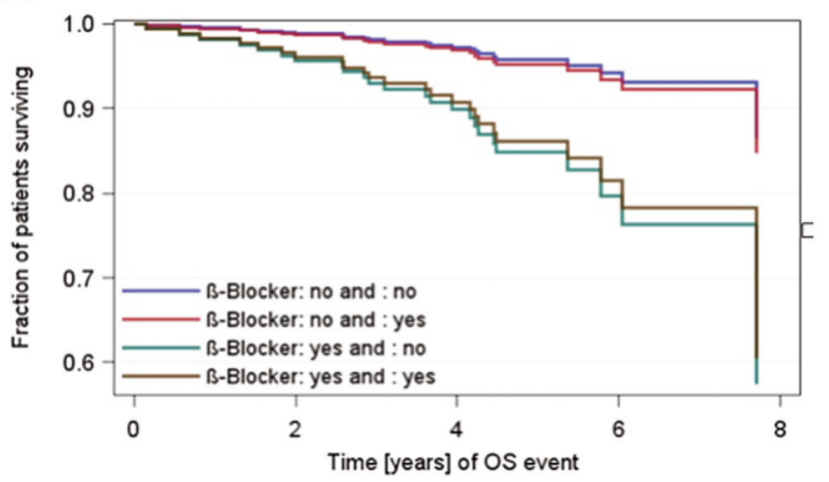

B

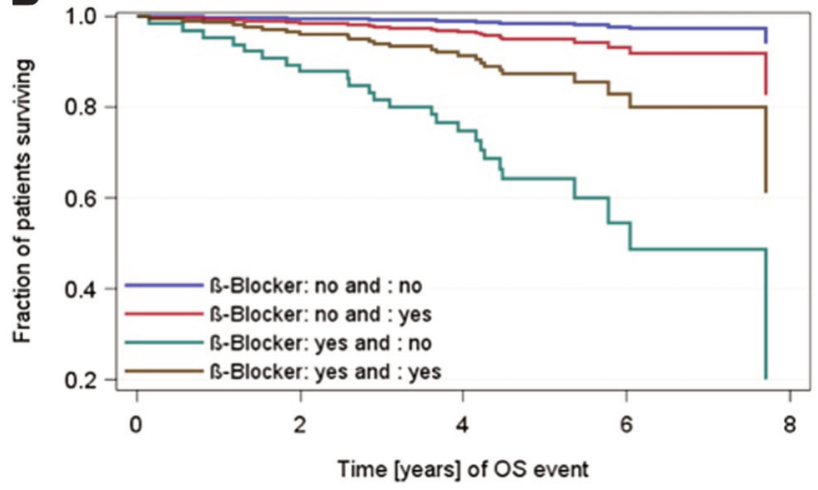

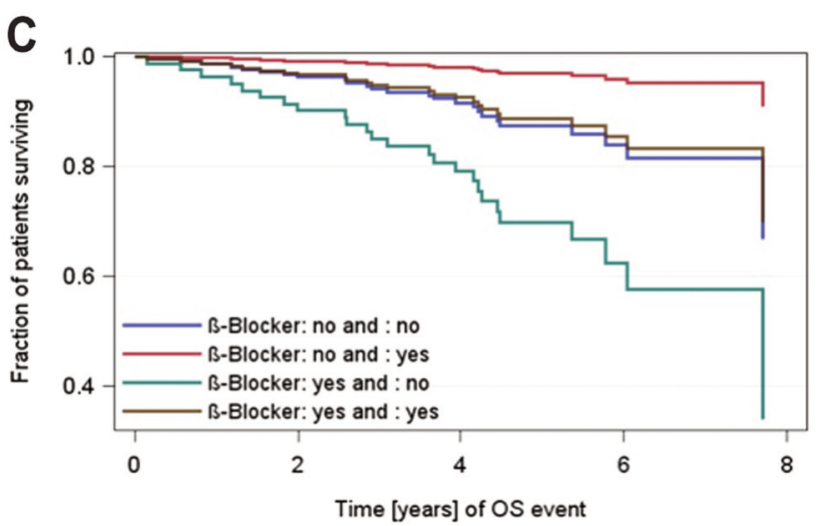

Figure 3. Patients were stratified according to treatment regimens with either chemotherapy (A) or radiotherapy (B) or endocrine therapy (C) and usage of beta-blockers resulting in four subsets of patients. Kaplan-Meier analysis showed that A) among patients receiving chemotherapy, OS was significantly decreased when beta-blockers were used (HR=3.03; 95\% CI=1.01-9.06; $p=0.05)$, B) Patients undergoing radiotherapy and using betablockers had a significantly decreased $O S$ (HG=2.6; 95\% CI=1.08-6.32; $p=0.03)$ and C) Patients receiving endocrine therapy and using betablockers had a significantly decreased $O S(H R=3.8 ; 95 \% C I=1.29-10.99 ; p=0.01)$.

Furthermore, bivariate Cox regression analysis showed that OS was associated with beta-blocker treatment and histologic features of the tumor (Figure 2). In both groups, patients with ductal or lobular breast cancer, OS was significantly decreased when beta-blockers were used $(\mathrm{HR}=$ 3.4; 95\% CI=1.22-9.38; $p=0.02$ and $\mathrm{HR}=5.8$; 95\% CI=1.04$2.38 ; p=0.05$, respectively). Patients with ductal breast cancer not receiving beta-blocker treatment could benefit most from prolonged OS. The worst prognosis was identified for patients with lobular breast cancer that were using betablockers.

Significant correlations could also be demonstrated for OS, beta-blocker use and chemotherapeutic treatment (Figure 3A). Bivariate cox regression showed that OS was significantly longer in patients undergoing chemotherapy and no intake of beta-blockers $(\mathrm{HR}=3.8 ; 95 \% \mathrm{CI}=1.10-3.29$; $p=0.03)$. Regardless of whether patients received chemotherapy or not, they had significantly decreased OS when using beta-blockers. Similar results were obtained for patients undergoing radiotherapy in combination with betablockers (Figure 3B). Patients not receiving radiotherapy and beta-blocker treatment survived significantly longer $(\mathrm{HR}=25.8 ; 95 \% \mathrm{CI}=2.65-50.55 ; p=0.01)$ as compared to patients undergoing radiotherapy and beta-blocker treatment $(\mathrm{HR}=2.6 ; 95 \% \quad \mathrm{CI}=1.08-6.32 ; p=0.03)$. Bivariate cox regression analysis with regard to endocrine therapy and beta-blocker treatment (Figure 3C) revealed that patients survived significantly longer when receiving endocrine therapy but no beta-blockers $(\mathrm{HR}=0.24 ; 95 \% \mathrm{CI}=0.08-0.68$; $p=0.01)$. Patients undergoing endocrine therapy and betablocker treatment had a significantly decreased OS $(\mathrm{HR}=3.8$; 95\% CI=1.29-10.99; $p=0.01)$.

Bivariate analysis revealed that ER-status and beta-blocker treatment was significantly correlated with OS (Figure 4A). OS was significantly decreased in ER-positive patients using beta-blockers $(\mathrm{HR}=4.3 ; 95 \% \mathrm{CI}=1.53-11.92, p=0.01)$. Patients with positive ER-status and with no beta-blocker treatment could benefit most as compared to ER-negative patients. 

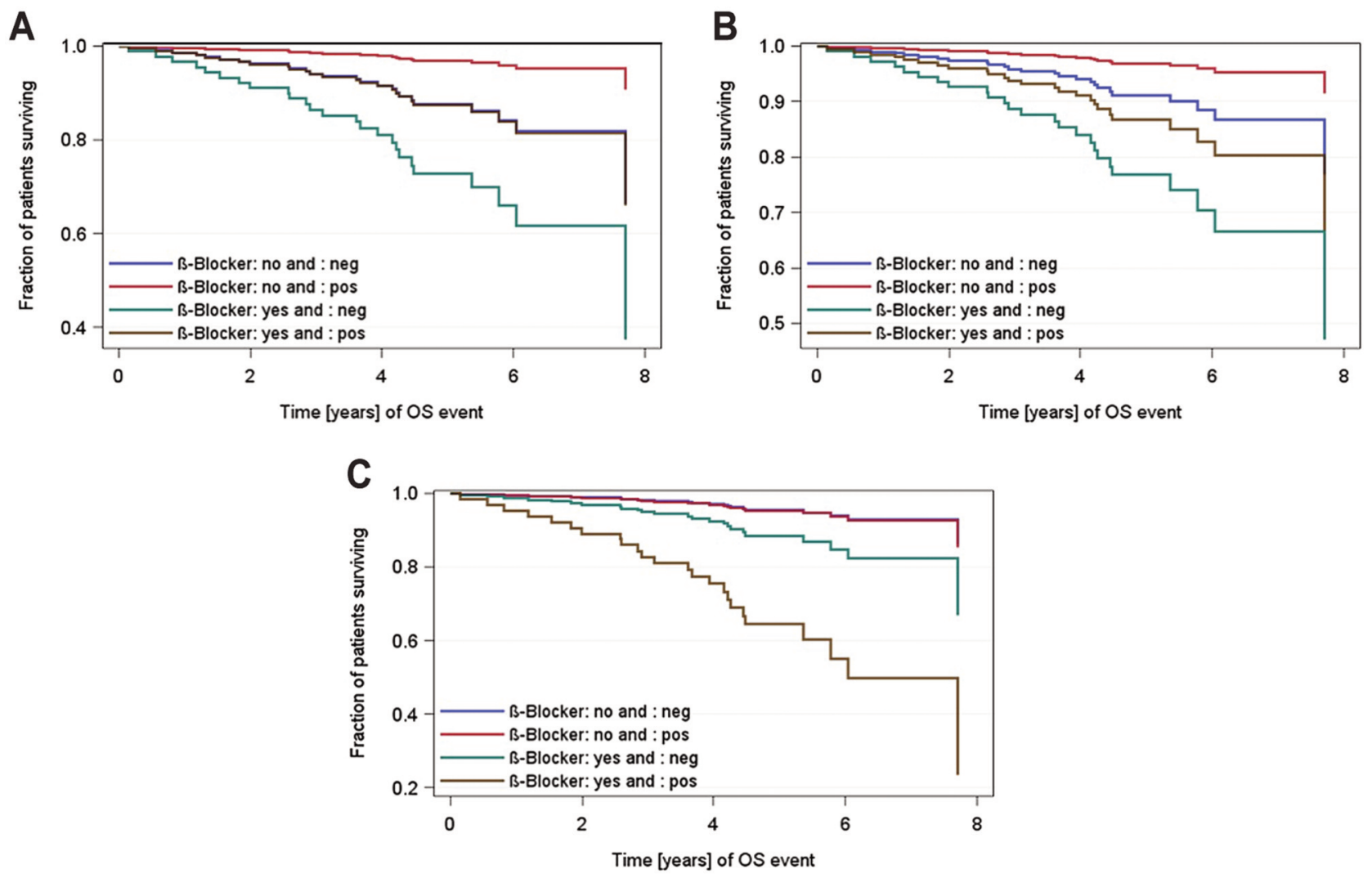

Figure 4. Patients were stratified into beta-blocker usage according to receptor status, A) ER-positive or -negative, B) PR-positive or -negative, C) HER2-positive or-negative. Kaplan-Meier analysis showed that A) in patients without beta-blocker usage, OS was significantly increased when ER status was positive $(H R=0.2 ; 95 \% C I=0.08-0.69 ; p=0.01)$. B) PR-positive patients without beta-blocker usage survived significantly longer (HR=0.3; 95\% CI=0.12-0.97; $p=0.04 ;)$ as compared to those using beta-blockers (HR=4.5; 95\% CI=1.57-12.94; $p=0.01)$. C) OS was significantly decreased in HER2-negative and -positive patients when beta-blockers were used (HR=2.6; 95\% CI=1.04-6.75; $p=0.04$ and HR=9.1; 95\% CI=1.50-55.11; $p=0.02$, respectively).

Similar results were obtained when analyzing the progesterone receptor (PR) status, beta-blocker usage and survival. PR-positive patients with no usage of beta-blockers survived significantly longer $(\mathrm{HR}=0.3 ; 95 \% \mathrm{CI}=0.12-0.97$; $p=0.04)$ as compared to those patients using beta-blockers ( $\mathrm{HR}=4.5 ; 95 \% \mathrm{CI}=1.57-12.94 ; p=0.01$ ) (Figure 4b). The correlation between HER2 status, beta-blocker treatment and survival (Figure 4C) revealed that HER2-negative and -positive patients had a significantly decreased OS when betablockers were used $(\mathrm{HR}=2.6 ; 95 \% \mathrm{CI}=1.04-6.75 ; p=0.04$ and $\mathrm{HR}=9.1 ; 95 \% \mathrm{CI}=1.50-55.11 ; p=0.02$, respectively).

\section{Discussion}

The primary aim of our study was to investigate the possible effects of lifestyle factors on the prognosis of breast cancer survivors. Our findings indicate that a low BMI might be associated with prolonged PFS and are in line with a study by Flegal et al. (26). They also correlated different obesity levels with mortality and were able to demonstrate that a relatively low BMI between $25-30 \mathrm{~kg} / \mathrm{m}^{2}$ was associated to a better OS (26).

Cigarette smoking did not significantly influence the survival probability of breast cancer patients in our cohort, even though it has been controversially discussed to be a possible risk factor for breast cancer. However, it is not yet clear, to which extend cigarette smoking might impact survival time. Processing retrospective patient data makes the investigator dependent on the quality of the medical reports. The questionnaire used in this study population referred to cigarette smoking only at the time of diagnosis, thus, neglecting possible periods of smoking before or after.

Furthermore, we could not find any prognostic effects of alcohol intake or atopic diseases. Extensive literature review did not reveal associations with the prognosis of breast cancer survivors. Regarding alcohol consumption as documented in the medical reports, it is possible that patients might not have been honest in declaring their real consumption. 
The most interesting finding obtained from this study is the impact of beta-blocker usage on the prognosis of breast cancer patients. Several statistical analyses demonstrated that patients not receiving beta-blockers had a significant survival benefit as compared to beta-blocker users. Apparently, clincopathological parameters such as HER2-, ER- and PRstatus as well as treatment with chemo-, radio- and endocrine therapy did not play a role regarding the survival difference between beta-blocker users and non-users. Interestingly, patients without beta-blocker treatment seemed to have an even better prognosis when they were overweight (BMI $>30$ $\mathrm{kg} / \mathrm{m}^{2}$ ). However, these results might be biased as obese patients were less frequent smokers and had a slightly smaller alcohol intake. Moreover, patients with a BMI $\geq 30 \mathrm{~kg} / \mathrm{m}^{2}$ were more often using Metformin, which is suspected to have a positive effect on the OS of breast cancer patients (27). Even though the survival analysis revealed no significant benefit in terms of OS for patients taking Metformin, the statistical trend in combination with the smoking and alcohol intake might be enough to explain this finding. In this regard, whether the elevated BMI really has a protective effect on the OS is not clear and needs to be studied further.

In contrast, preclinical investigations suggested rather positive associations between beta-blocker intake and reduction of recurrence as well as improved clinical outcome. Notably, our findings are in line with the largest cohort presented by a Danish nationwide prospective cohort study which was unable to confirm the hypothesis that beta-blockers attenuated breast cancer recurrence risk (28). Considering that patients using beta-blockers were mostly elder ( $>60$ years) and overweight (BMI $>30 \mathrm{~kg} / \mathrm{m}^{2}$ ), it is possible that they were suffering from metabolic disorders like hypertension, dyslipoproteinemia, type 2 diabetes or obesity which are well-known cardiovascular risk factors and associated with increased mortality. Hence, in our study, the survival decrease revealed in breast cancer survivors using beta-blockers might be related to metabolic disorders as well as the treatment thereof.

A study by Goodwin et al. (29) analyzed patients with metabolic syndrome and found increased levels of circulating insulin and insulin-like growth factor-1 (IGF-1) that might give rise to a greater risk of breast cancer. In addition, reduction of sex-hormone-binding globulin levels and increased estrogen bioavailability, due to hyperinsulinemia, were thought to be responsible for elevated breast cancer risk (30). The intake of metformin might be an indicator for type 2 diabetes in our cohort. Metformin was reported to have positive effects on the survival of breast cancer patients (23, 31 ). Unfortunately, in our study, the number of patients using metformin was too small to receive statistically reliable results related to prognosis.

Furthermore, our data indicated a relationship between beta-blocker usage and nodal status at primary diagnosis of breast cancer. The majority of women diagnosed at NO were not using beta-blockers. Hence, they were likely to be younger, non-obese and without metabolic imbalances, suggesting a better overall health condition and therefore, better treatment response as compared to patients using betablockers. Further lifestyle investigation studies that will focus in more detail onto co-morbidities and innovative life style associated parameters need to be initiated to conclusively answer the question of whether lifestyle matters.

\section{Conclusion}

This retrospective observational study indicated a significant association between beta-blocker intake and prognosis of breast cancer survivors. Patients not using beta-blockers appeared to benefit from extended PFS and OS. Furthermore, patients with a relatively low BMI $\left(<30 \mathrm{~kg} / \mathrm{m}^{2}\right)$ seemed to have a survival benefit as compared to obese patients. Particularly, among postmenopausal women, beta-blocker intake and obesity appeared to be possible lifestyle related prognostic factors that might be used for patient stratification. Individual profiling of patients based on adequate life stylerelated parameters might help to identify patients at high risk.

\section{Conflicts of Interest}

The Authors declare that they have no conflicts of interest.

\section{Authors' Contributions}

Anne Kreklau: Conceptualization, Data curation, Formal analysis Investigation, Methodology, Project administration, Validation, Visualization, Writing-original draft. Ivonne Nel: Conceptualization, Formal analysis, Investigation, Methodology, Project administration, Visualization, Writing - original draft. Anna Christina Frackenpohl: Conceptualization, Formal analysis, Investigation, Methodology, Project administration, Visualization, Writing - original draft. Rainer Kimmig: Conceptualization, Data curation, Funding acquisition, Investigation, Methodology, Project administration, Resources, Software, Writing - review and editing. Sabine Kasimir-Bauer: Conceptualization, Data curation, Formal analysis, Funding acquisition, Investigation, Methodology, Project administration, Resources, Software, Writing - review and editing. Bahriye Aktas: Conceptualization, Data curation, Formal analysis, Funding acquisition, Investigation, Methodology, Project administration, Resources, Software, Writing - review and editing.

\section{References}

1 Bray F, Ferlay J, Soerjomataram I, Siegel RL, Torre LA and Jemal A: Global cancer statistics 2018: Globocan estimates of incidence and mortality worldwide for 36 cancers in 185 countries. CA Cancer J Clin 68(6): 394-424, 2018. PMID: 30207593. DOI: $10.3322 /$ caac. 21492

2 Waks AG and Winer EP: Breast cancer treatment: A review. JAMA 321(3): 288-300, 2019. PMID: 30667505. DOI: 10.1001/ jama.2018.19323 
3 van Gemert WA, Lanting CI, Goldbohm RA, van den Brandt PA, Grooters HG, Kampman E, Kiemeney L, van Leeuwen FE, Monninkhof EM, de Vries E, Peeters PH and Elias SG: The proportion of postmenopausal breast cancer cases in the netherlands attributable to lifestyle-related risk factors. Breast Cancer Res Treat 152(1): 155-162, 2015. PMID: 26044369. DOI: $10.1007 / \mathrm{s} 10549-015-3447-7$

4 Schoemaker MJ, Nichols HB, Wright LB, Brook MN, Jones ME, O'Brien KM, Adami HO, Baglietto L, Bernstein L, Bertrand KA, Boutron-Ruault MC, Braaten T, Chen Y, Connor AE, Dorronsoro M, Dossus L, Eliassen AH, Giles GG, Hankinson SE, Kaaks R, Key TJ, Kirsh VA, Kitahara CM, Koh WP, Larsson SC, Linet MS, Ma H, Masala G, Merritt MA, Milne RL, Overvad K, Ozasa K, Palmer JR, Peeters PH, Riboli E, Rohan TE, Sadakane A, Sund M, Tamimi RM, Trichopoulou A, Ursin G, Vatten L, Visvanathan K, Weiderpass E, Willett WC, Wolk A, Yuan JM, ZeleniuchJacquotte A, Sandler DP and Swerdlow AJ: Association of body mass index and age with subsequent breast cancer risk in premenopausal women. JAMA Oncol 4(11): e181771, 2018. PMID: 29931120. DOI: 10.1001/jamaoncol.2018.1771

5 Ghosn B, Benisi-Kohansal S, Ebrahimpour-Koujan S, Azadbakht L and Esmaillzadeh A: Association between healthy lifestyle score and breast cancer. Nutr J 19(1): 4, 2020. PMID: 31937325. DOI: $10.1186 / \mathrm{s} 12937-020-0520-9$

6 Key TJ, Bradbury KE, Perez-Cornago A, Sinha R, Tsilidis KK and Tsugane S: Diet, nutrition, and cancer risk: What do we know and what is the way forward? BMJ 368: m511, 2020. PMID: 32139373. DOI: 10.1136/bmj.m511

7 Schienkiewitz A, Mensink G, Kuhnert R and Lange C: Übergewicht und adipositas bei erwachsenen in Deutschland. J Health Monit 2(2): 21-28, 2017. DOI: 10.17886/RKI-GBE-2017-025

8 Ma $\mathrm{H}$, Ursin $\mathrm{G}, \mathrm{Xu} \mathrm{X}$, Lee E, Togawa $\mathrm{K}$, Malone KE, Marchbanks PA, McDonald JA, Simon MS, Folger SG, Lu Y, Sullivan-Halley J, Deapen DM, Press MF and Bernstein L: Body mass index at age 18 years and recent body mass index in relation to risk of breast cancer overall and er/pr/her2-defined subtypes in white women and african-american women: A pooled analysis. Breast Cancer Res 20(1): 5, 2018. PMID: 29357906. DOI: 10.1186/s13058-017-0931-5

9 Kyrgiou M, Kalliala I, Markozannes G, Gunter MJ, Paraskevaidis E, Gabra H, Martin-Hirsch P and Tsilidis KK: Adiposity and cancer at major anatomical sites: Umbrella review of the literature. BMJ 356: j477, 2017. PMID: 28246088. DOI: 10.1136/bmj.j477

10 Picon-Ruiz M, Morata-Tarifa C, Valle-Goffin JJ, Friedman ER and Slingerland JM: Obesity and adverse breast cancer risk and outcome: Mechanistic insights and strategies for intervention. CA Cancer J Clin 67(5): 378-397, 2017. PMID: 28763097. DOI: $10.3322 /$ caac. 21405

11 Trentham-Dietz A, Newcomb PA, Nichols HB and Hampton JM: Breast cancer risk factors and second primary malignancies among women with breast cancer. Breast Cancer Res Treat 105(2): 195-207, 2007. PMID: 17186360. DOI: 10.1007/s10549006-9446-y

$12 \mathrm{Li}$ CI, Daling JR, Porter PL, Tang MT and Malone KE: Relationship between potentially modifiable lifestyle factors and risk of second primary contralateral breast cancer among women diagnosed with estrogen receptor-positive invasive breast cancer. J Clin Oncol 27(32): 5312-5318, 2009. PMID: 19738113. DOI: 10.1200/JCO.2009.23.1597
13 Rock CL, Flatt SW, Byers TE, Colditz GA, Demark-Wahnefried W, Ganz PA, Wolin KY, Elias A, Krontiras H, Liu J, Naughton M, Pakiz B, Parker BA, Sedjo RL and Wyatt H: Results of the exercise and nutrition to enhance recovery and good health for you (energy) trial: A behavioral weight loss intervention in overweight or obese breast cancer survivors. J Clin Oncol 33(28): 3169-3176, 2015. PMID: 26282657. DOI: 10.1200/ JCO.2015.61.1095

14 Garcia-Estevez L and Moreno-Bueno G: Updating the role of obesity and cholesterol in breast cancer. Breast Cancer Res 21(1): 35, 2019. PMID: 30823902. DOI: 10.1186/s13058-0191124-1

15 Blüher M: Obesity: Global epidemiology and pathogenesis. Nat Rev Endocrinol 15(5): 288-298, 2019. PMID: 30814686. DOI: 10.1038/s41574-019-0176-8

16 Ganz PA, Habel LA, Weltzien EK, Caan BJ and Cole SW: Examining the influence of beta blockers and ace inhibitors on the risk for breast cancer recurrence: Results from the lace cohort. Breast Cancer Res Treat 129(2): 549-556, 2011. PMID: 21479924. DOI: $10.1007 / \mathrm{s} 10549-011-1505-3$

17 Melhem-Bertrandt A, Chavez-Macgregor M, Lei X, Brown EN, Lee RT, Meric-Bernstam F, Sood AK, Conzen SD, Hortobagyi GN and Gonzalez-Angulo AM: Beta-blocker use is associated with improved relapse-free survival in patients with triplenegative breast cancer. J Clin Oncol 29(19): 2645-2652, 2011. PMID: 21632501. DOI: 10.1200/JCO.2010.33.4441

18 Barron TI, Connolly RM, Sharp L, Bennett K and Visvanathan $\mathrm{K}$ : Beta blockers and breast cancer mortality: A populationbased study. J Clin Oncol 29(19): 2635-2644, 2011. PMID: 21632503. DOI: $10.1200 / \mathrm{JCO} .2010 .33 .5422$

19 Childers WK, Hollenbeak CS and Cheriyath P: B-blockers reduce breast cancer recurrence and breast cancer death: A metaanalysis. Clin Breast Cancer 15(6): 426-431, 2015. PMID: 26516037. DOI: 10.1016/j.clbc.2015.07.001

20 Weberpals J, Jansen L, Carr PR, Hoffmeister M and Brenner H: Beta blockers and cancer prognosis - the role of immortal time bias: A systematic review and meta-analysis. Cancer Treat Rev 47: 1-11, 2016. PMID: 27179912. DOI: 10.1016/j.ctrv. 2016.04.004

21 Kim HY, Jung YJ, Lee SH, Jung HJ and Pak K: Is beta-blocker use beneficial in breast cancer? A meta-analysis. Oncology 92(5): 264-268, 2017. PMID: 28132057. DOI: 10.1159/ 000455143

$22 \mathrm{Li} \mathrm{C}$, Li T, Tang R, Yuan S and Zhang W: B-blocker use is not associated with improved clinical outcomes in women with breast cancer: A meta-analysis. Biosci Rep 40(6): BSR20200721, 2020. PMID: 32436935. DOI: 10.1042/BSR20200721

$23 \mathrm{Wu}$ L, Zhu J, Prokop LJ and Murad MH: Pharmacologic therapy of diabetes and overall cancer risk and mortality: A metaanalysis of 265 studies. Sci Rep 5: 10147, 2015. PMID: 26076034. DOI: 10.1038/srep10147

24 Lei Y, Yi Y, Liu Y, Liu X, Keller ET, Qian CN, Zhang J and Lu Y: Metformin targets multiple signaling pathways in cancer. Chin J Cancer 36(1): 17, 2017. PMID: 28126011. DOI: 10.1186/ s40880-017-0184-9

25 Type and timing of menopausal hormone therapy and breast cancer risk: Individual participant meta-analysis of the worldwide epidemiological evidence. Lancet 394(10204): 11591168, 2019. PMID: 31474332. DOI: 10.1016/S0140-6736(19) 31709-X 
26 Flegal KM, Kit BK, Orpana H and Graubard BI: Association of all-cause mortality with overweight and obesity using standard body mass index categories: A systematic review and metaanalysis. JAMA 309(1): 71-82, 2013. PMID: 23280227. DOI: 10.1001/jama.2012.113905

27 Wang JC, Li GY, Wang B, Han SX, Sun X, Jiang YN, Shen YW, Zhou C, Feng J, Lu SY, Liu JL, Wang MD and Liu PJ: Metformin inhibits metastatic breast cancer progression and improves chemosensitivity by inducing vessel normalization via pdgf-b downregulation. J Exp Clin Cancer Res 38(1): 235, 2019. PMID: 31164151. DOI: 10.1186/s13046-019-1211-2

28 Sorensen GV, Ganz PA, Cole SW, Pedersen LA, Sorensen HT, Cronin-Fenton DP, Garne JP, Christiansen PM, Lash TL and Ahern TP: Use of beta-blockers, angiotensin-converting enzyme inhibitors, angiotensin ii receptor blockers, and risk of breast cancer recurrence: A danish nationwide prospective cohort study. J Clin Oncol 31(18): 2265-2272, 2013. PMID: 23650417. DOI: 10.1200/JCO.2012.43.9190
29 Goodwin PJ, Ennis M, Pritchard KI, Trudeau ME, Koo J, Madarnas Y, Hartwick W, Hoffman B and Hood N: Fasting insulin and outcome in early-stage breast cancer: Results of a prospective cohort study. J Clin Oncol 20(1): 42-51, 2002. PMID: 11773152. DOI: 10.1200/JCO.2002.20.1.42

30 Wallace IR, McKinley MC, Bell PM and Hunter SJ: Sex hormone binding globulin and insulin resistance. Clin Endocrinol (Oxf) 78(3): 321-329, 2013. PMID: 23121642. DOI: 10.1111/cen.12086

31 Samuel SM, Varghese E, Kubatka P, Triggle CR and Büsselberg D: Metformin: The answer to cancer in a flower? Current knowledge and future prospects of metformin as an anti-cancer agent in breast cancer. Biomolecules 9(12): 846, 2019. PMID: 31835318. DOI: $10.3390 /$ biom9120846

Received October 2, 2020

Revised January 21, 2021

Accepted January 26, 2021 